\title{
Tracing cytotoxic effects of small organic Se species in human liver cells back to total cellular Se and Se metabolites $\dagger$
}

\author{
T. A. Marschall, ${ }^{a}$ N. Kroepfl, ${ }^{b}$ K. B. Jensen, ${ }^{b}$ J. Bornhorst, ${ }^{a}$ B. Meermann, ${ }^{c}$ D. Kuehnelt, ${ }^{b}$ T. \\ Schwerdtle*a
}

\begin{abstract}
Small selenium (Se) species play a major role in the metabolism, excretion and dietary supply of the essential trace element selenium. Human cells provide a valuable tool for investigating currently unresolved issues on the cellular mechanisms of Se toxicity and metabolism. In this study, we developed two isotope dilution inductively coupled plasma tandem mass spectrometry based methods and applied them to human hepatoma cells (HepG2) in order to quantitatively elucidate total cellular Se concentrations and cellular Se species transformations in relation to the cytotoxic effects of four small organic Se species. Species- and incubation time-dependent results were obtained: The two major urinary excretion metabolites trimethylselenonium (TMSe) and methyl-2-acetamido-2-deoxy-1-seleno- $\beta$-D-galactopyranoside (SeSugar 1 ) were taken up by the HepG2 cells in an unmodified manner and did not considerably contribute to the Se pool. In contrast, methylselenocysteine (Se-MeSeCys) and selenomethionine (SeMet) were taken up in higher amounts, they were largely incorporated by the cells (most likely into proteins) and metabolized to other small Se species. Two new metabolites of MeSeCys, namely $\mathbf{\gamma}$-glutamy-Se-methylselenocysteine and Se-methylselenoglutathione, were identified by means of HPLCelectrospray-ionization-Orbitrap-MS. They are certainly involved in the (de-)toxification modes of Se metabolism and require further investigation.
\end{abstract}

\section{Introduction}

As the essential trace element selenium (Se) may exert toxic effects following elevated uptake, adequate supply has to be within a narrow corridor and Se intake recommendations are of great concern. ${ }^{1,2}$ A recent review ${ }^{3}$ claimed that the beneficial range of Se uptake might be even lower than the recommended daily intake of $60-70 \mu \mathrm{g} \mathrm{Se} / \mathrm{d},{ }^{4}$ while other studies presented health-promoting effects of additional Se supplementation. Apart from selenoproteins fulfilling manifold essential functions, low molecular weight Se containing molecules are of central importance for Se metabolism as excretion metabolites and as Se food source. ${ }^{5}$

In various epidemiological and intervention studies regarding diseases like cancer, diabetes, cardiovascular and neurodegenerative disorders beneficial as well as adverse outcomes have been linked to Se supplementation with partly conflicting results. ${ }^{6}$ Apart from the Se dosage and baseline

\footnotetext{
a. Institute of Nutritional Science, University of Potsdam, Arthur-Scheunert-Allee 114-116, 14558 Nuthetal, Germany

b. Institute of Chemistry, Analytical Chemistry, NAWI Graz, University of Graz, Universitaetsplatz 1, $8010 \mathrm{Graz}$, Austria

c. Federal Institute of Hydrology, Department G2 - Aquatic Chemistry, Am Mainzer Tor 1, 56068 Koblenz, Germany
}

* Corresponding author address: Institute of Nutritional Science, University of Potsdam, Arthur-Scheunert-Allee 114-116, 14558 Nuthetal, Germany, Phone: +49-33200/88-5573, Fax: +49-33200/88-5573, Email: tanja.schwerdtle@unipotsdam.de status at the beginning of supplementation, the administered form of Se has a decisive impact on the results. ${ }^{7}$ As one important dietary Se source selenomethionine (SeMet) ubiquitously occurs in various proteins, in which it is nonspecifically incorporated instead of methionine and serves as long-term Se storage in vivo.8,9 Se-methylselenocysteine (MeSeCys) is a plant metabolite, which is present in Allium and Brassicaceae species. ${ }^{10}$ It has been shown to release methylselenol (MeSeH) in vitro and in vivo, which is currently discussed to possess anti-cancer properties. ${ }^{11,12}$ So far MeSeCys is not authorized as Se supplement in the European Union in contrast to inorganic selenite and selenate, SeMet and selenium-enriched yeast, which may contain up to $10 \%$ organic Se species other than SeMet (including MeSeCys). ${ }^{13}$ Excess Se is mainly excreted via urine as selenosugars (SeSugar) and, depending on individual genetic variances, ${ }^{14}$ as trimethylselenonium ion (TMSe). ${ }^{5}$

Human in vitro models enable to explore fundamental roots of the strongly species-dependent effects under cytotoxic conditions. One likely reason is the formation of different metabolites, which may either diminish or enhance the toxicity of the original species. Consequently, speciation studies in human cell models may help to shed light on the speciesspecific mechanisms and metabolites, which potentially influence the differing cytotoxic effects. For this purpose, a few speciation studies have been carried out applying high performance liquid chromatography inductively coupled plasma-mass spectrometry (HPLC-ICP-MS) or X-ray absorption techniques to human cells. For instance, Weekley et al. 
presented evidences, that a diselenide compound is responsible for more pronounced redox-altering cytotoxic effects of MeSeCys in comparison to SeMet in neuroblastoma cells. ${ }^{15}$ In leukemia, prostate and colon cancer cells as well as in urothelial cells, no correlation was discovered between total Se, cell death and cellular Se species. ${ }^{16,17}$ No metabolites, which might have been responsible for the cytotoxic effects, were found for MeSeCys and SeMet in the first three cell lines. ${ }^{16}$ In the urothelial cells two unknown metabolites of MeSeCys were detected. ${ }^{17}$ So far mainly qualitative speciation data have been presented, which do not permit to compare cellular species concentrations.

This study aims to unveil potential causes for the differing cytotoxic effects of MeSeCys, SeMet, TMSe and methyl-2acetamido-2-deoxy-1-seleno- $\beta$-D-galactopyranoside (SeSugar 1) by quantitatively investigating differences in their uptake and metabolism by isotope dilution (ID) ICP-tandem mass spectrometry (ICP-QQQ-MS) and species unspecific postcolumn online ID-HPLC-ICP-QQQ-MS. As the liver represents an important site for Se metabolism, ${ }^{2}$ human hepatoma cells (HepG2) were chosen as cellular model system. All four small species have been detected in serum following Se supplementation. ${ }^{18-20}$ Consequently, they are likely to reach the liver or, in the cases of TMSe and SeSugar 1, to be formed in the liver. The HepG2 cell line offers the advantage of being a wellestablished liver cell model with broad applications. ${ }^{21,22}$ As it is a cancer cell line, additional information concerning cancerinhibiting properties can be collected when investigating cytotoxic effects.

\section{Experimental}

\section{Materials}

The HepG2 cell line was obtained from the European Collection of Authenticated Cell Cultures (ECACC 85011430, Salisbury, UK). Minimum essential medium Eagle (MEM) and non-essential amino acids (NEA) were purchased from Biochrom (Berlin, Germany). Fetal calf serum (FCS) was from PAA laboratories (Cölbe, Germany). Trypsin and penicillin-streptomycin (PS) were obtained from Sigma-Aldrich (Steinheim, Germany). Culture dishes were from TPP (Trasadingen, Switzerland) and Biochrom (Berlin, Germany).

The natural elemental Se standard ( $1 \mathrm{~g} / \mathrm{L})$ was supplied by Merck (Darmstadt, Germany) and isotopically enriched ${ }^{77} \mathrm{Se}$ $\left(97.20 \pm 0.20 \%{ }^{77} \mathrm{Se} ; 0.10 \%{ }^{74} \mathrm{Se} ; 0.40 \pm 0.10 \%{ }^{76}\right.$ Se; $2.40 \pm 0.10 \%$ ${ }^{78} \mathrm{Se} ; 0.10 \%{ }^{80} \mathrm{Se} ; 0.10 \%{ }^{82} \mathrm{Se}$ as certified by Trace Sciences International (Ontario, Canada)) was purchased from Eurisotop SAS (Saarbrücken, Germany). D/L-SeMet ( $\geq 99 \%$ ) was obtained from Sigma-Aldrich (Steinheim, Germany). L-MeSeCys (> 98\%) was from Abcam (Cambridge, UK). TMSe and SeSugar 1 were synthesized according to published protocols at the University of Graz, Institute of Chemistry - Analytical Chemistry 23,24 with data on the identity and purity of these molecules having been published elsewhere. ${ }^{23}$ As reference materials fish muscle ERM $^{\circledR}$ - BB422 from the Institute for Reference Materials and Measurements (European Commission, Geel, Belgium) and ClinChek $^{\circledR}$ lyophilized control serum for trace elements (Level I and Level II) from Recipe (Munich, Germany) were used. Nitric acid $\left(\mathrm{HNO}_{3}\right)(65 \%$, suprapur) was purchased from Merck (Darmstadt, Germany). Ammonium formate ( $\geq 99.995 \%)$ as well as isopropanol ( $\geq 99.999 \%$ ) were from Sigma Aldrich (Steinheim, Germany). Formic acid (99\% for analysis) was obtained from Acros Organics (Geel, Belgium) and methanol (LC-MS grade) from VWR (Darmstadt, Germany). All further chemicals were of pro analysi grade from Sigma-Aldrich (Steinheim, Germany), Alfa Aesar (Karlsruhe, Germany), Roth (Karlsruhe, Germany) or Merck (Darmstadt, Germany). Water applied in the experiments was always purified using a water purification system (10 $\mathrm{M} \Omega \mathrm{cm}$, Elix ${ }^{\circledR} 15$, Merck Millipore).

For the metabolite identification experiments by HPLCelectrospray-ionization-high resolution accurate mass-MS (HPLC-ESI-HR-MS), ammonium formate ( $\geq 95 \%$ ) and ammonia solution (25\%, p.a.) were purchased from Carl Roth GmbH \& Co. KG (Karlsruhe, Germany). Methanol (HPLC gradient grade) was obtained from VWR International (Fontenay-sous-Bois, France).

\section{Preparation of Se species stock solutions and ${ }^{77}$ Se spike solution}

Se species stock solutions $(10-40 \mathrm{mM})$ were prepared and further diluted in sterile water and stored at $4{ }^{\circ} \mathrm{C} .17$ Their concentrations and purity were frequently verified by HPLC-ICPQQQ-MS (data not shown). The ${ }^{77}$ Se spike stock solution (100 $\mathrm{mg} / \mathrm{L}, 2 \% \mathrm{HNO}_{3}$ ) was prepared by dissolving a few $\mathrm{mg}$ of solid, isotopically enriched ${ }^{77} \mathrm{Se}$ in $1 \mathrm{~mL}$ of concentrated, nitric acid within $48 \mathrm{~h}$ at room temperature and subsequent further dilution with water. Isotopic composition of this solution was measured by ICP-QQQ-MS. It was in good agreement with the certified values obtained from the manufacturer. The spike stock solution was further diluted to $100 \mu \mathrm{g} / \mathrm{L}$ (for total Se analysis) or $5 \mathrm{\mu g} / \mathrm{L}$ (for speciation analysis) in $2 \% \mathrm{HNO}_{3}$ in order to obtain the spike solutions. Their concentrations were determined by reverse ID against a natural Se standard owing the respective concentration in $2 \% \mathrm{HNO}_{3}$, which was obtained by diluting the natural elemental Se standard $(1 \mathrm{~g} / \mathrm{L})$.

\section{Culturing and incubating HepG2 cells}

The cultivation of HepG2 cells was carried out as already described. ${ }^{17}$ Briefly, HepG2 cells were grown as monolayers on plastic culture dishes in MEM medium supplemented with $10 \%$ fetal calf serum (FCS), PS (100 U/mL) and NEA (1\% v/v) at $37{ }^{\circ} \mathrm{C}$ in $5 \% \mathrm{CO}_{2}$ and $100 \%$ atmospheric humidity. Culture splitting was performed every two to three days using $0.25 \%$ trypsin. For incubation experiments, 8000 cells per $\mathrm{cm}^{2}$ were seeded and allowed to proliferate for $24 \mathrm{~h}$. Subsequently, incubations with the respective Se species were carried out for $48 \mathrm{~h}$ or $4 \mathrm{~d}$.

\section{Cell number measurement and preparation of cell pellets and lysates}

Upon incubation period expiry, cell culture medium was removed, cells were washed twice with $37{ }^{\circ} \mathrm{C}$ warm PBS and trypsinized as described earlier. ${ }^{17}$ Cells were detached and resuspended with ice-cold PBS supplemented with 5\% FCS. An 
aliquot was analyzed regarding cell number, cell volume and cell aggregation using an automated cell counting system (Casy TTCS, Roche Innovatis AG, Bielefeld, Germany). Following 5 min of centrifugation at $4{ }^{\circ} \mathrm{C}$ and $300 \times \mathrm{g}$, the supernatant was discarded and cells were carefully washed with ice-cold PBS, centrifuged ( $5 \mathrm{~min}, 4^{\circ} \mathrm{C}$ and $600 \mathrm{xg}$ ) again and once more the supernatant was rejected and the cell pellet was obtained. In order to fragment the cell pellet into a water-soluble and a water-insoluble part, $200 \mu \mathrm{L}$ of cooled sterile water was added to the pellet. Following sonication (15 s, 0.8 cycles, 100\% amplitude) on ice and centrifugation $\left(4^{\circ} \mathrm{C}, 10 \mathrm{~min}, 21000 \times \mathrm{g}\right.$ ) the water-soluble cell fraction (lysates) and the water-insoluble cell components were obtained as supernatant and small solid residue, respectively. The detached cells and all fractions derived thereof were continuously cooled. Speciation analysis was performed on the same day of cell pellet preparation. For total Se analysis samples were stored at $-20^{\circ} \mathrm{C}$.

\section{Sample preparation for total Se measurement}

In order to gain information on total cellular Se as well as on the Se species present in the cell lysates from one incubation experiment, total Se was quantified separately in the lysates and in the residues, as the sum of both corresponds to the Se concentration in the whole cell pellet. The residues were prepared by microwave-assisted acid digestion with a MARS 6 system (CEM, Kamp-Lintfort, Germany) using the previously published method with slight modifications. ${ }^{17}$ Briefly, the residues were completely transferred into microwave digestion vessels ( $20 \mathrm{~mL}$ closed TFA vessels) with $1.5 \mathrm{~mL}$ of a digestion mixture containing $30 \% \mathrm{HNO}_{3}$ and $5 \mu \mathrm{g} / \mathrm{L}{ }^{77} \mathrm{Se}$. Digestion was carried out applying $650 \mathrm{~W}$ to ramp the temperature to $200{ }^{\circ} \mathrm{C}$ within $15 \mathrm{~min}$ and keeping it for additional $20 \mathrm{~min}$. After cooling, the samples were filled up to $2.5 \mathrm{~mL}$ with water resulting in final concentrations of $3 \mu \mathrm{g} / \mathrm{L}{ }^{77} \mathrm{Se}$ and $20 \% \mathrm{HNO}_{3}$. Regarding the lysates, no digestion was performed because these samples were already obtained as clear solutions. An aliquot of the lysates was diluted with nitric acid and ${ }^{77} \mathrm{Se}(100 \mu \mathrm{g} / \mathrm{L})$ in order to obtain a solution with $3 \mu \mathrm{g} / \mathrm{L}{ }^{77} \mathrm{Se}$ and $2 \% \mathrm{HNO}_{3}$.

With regard to the reference materials, $250 \mu \mathrm{L}$ of reference serum (ClinCheck ${ }^{\circledR}$ ) was mixed with $675 \mu \mathrm{L}$ water, $500 \mu \mathrm{L} \mathrm{HNO}_{3}$ (65\%) and $75 \mu \mathrm{L}{ }^{77} \mathrm{Se}(100 \mu \mathrm{g} / \mathrm{L})$. This mixture was subjected to microwave-assisted acid digestion under the same digestion conditions as described above and the digested solution was subsequently filled up to $2.5 \mathrm{~mL}$ with water. Accordingly, 10-20 $\mathrm{mg}$ of fish muscle reference material (ERM $\left.{ }^{\circledR}-\mathrm{BB} 422\right)$ was digested with $2 \mathrm{~mL}$ nitric acid (65\%), $300 \mu \mathrm{L}{ }^{77} \mathrm{Se}(100 \mu \mathrm{g} / \mathrm{L})$ and $2 \mathrm{~mL}$ water and afterwards filled up to $10 \mathrm{~mL}$ with water.

\section{Total Se quantification by ID ICP-QQQ-MS}

Total Se was measured in the samples with an ICP-QQQ-MS 8800 system (Agilent, Waldbronn, Germany) with a MicroMist nebulizer, a Scott-type spray chamber and nickel sampler and skimmer cones applying ID. As described in detail elsewhere ${ }^{25}$ a sensitivity enhancement for Se is obtainable via the addition of small amounts of organic solvent. Thus, isopropanol was permanently added via a T-piece to the sample flow from the peristaltic pump by an additional HPLC pump (Merck Hitachi L$6200 \mathrm{~A})$ at a flow rate of $10 \mu \mathrm{L} / \mathrm{min}$ corresponding to $3 \%$ of carbon addition during ICP-QQQ-MS analysis. The flow rate was checked regularly and proved to be sufficiently constant. Se detection was performed with oxygen and hydrogen as reaction gases in the reaction and collision cell, which successfully eliminated spectral interferences. The most abundant Se isotopes ${ }^{80} \mathrm{Se}$ and ${ }^{78} \mathrm{Se}$ as well as ${ }^{77} \mathrm{Se}$ as isotopic spike were detected on mass and in mass shift mode as oxygen reaction products ( $m / z 16)$. Thus, Q1 filtered $m / z 77,78$ and 80 and upon reaction with oxygen or hydrogen either on mass or mass shifts were filtered in Q2: $\mathrm{m} / \mathrm{z} 77,93 ; 78,94$ and 80, 96 (ICPQQQ-MS parameters: supplementary table 1, Electronic Supplementary Information (ESI) ${ }^{17}$ ). The instrumental set-up is schematically depicted in supplementary figure $1, \mathrm{ESI}$.

For data analysis, the on mass raw counts were referred to the on mass transition of $m / z 77 \rightarrow 77$, while the mass shift raw counts were referred to the mass shift transition of $m / z 77 \rightarrow$ 93 , respectively. Subsequently, external mass bias correction was performed as described by Vogl and Pritzkow. ${ }^{26}$ Dead time correction was automatically accomplished by the instrument using 33 ns. The corrected isotope ratios were transformed into the corresponding concentrations applying the ID equation. ${ }^{27}$ For quantification $m / z \frac{80 \rightarrow 96}{77 \rightarrow 93}$ was used. $m / z \frac{80 \rightarrow 80}{77 \rightarrow 77}, \frac{78 \rightarrow 94}{77 \rightarrow 93}$ and $\frac{78 \rightarrow 78}{77 \rightarrow 77}$ transitions were used to uncover interferences, as all transitions lead to equal results, if no spectral overlaps occur. For validation of the ID ICP-QQQ-MS method, limits of detection and quantification (LOD and LOQ) were determined by measuring a blank solution containing $3 \mu \mathrm{g} / \mathrm{L}{ }^{77} \mathrm{Se}$ in $2 \% \mathrm{HNO}_{3}$ ten times. The isotopic ratios $\left(\mathrm{m} / \mathrm{z} \frac{80 \rightarrow 96}{77 \rightarrow 93}, \frac{80 \rightarrow 80}{77 \rightarrow 77}, \frac{78 \rightarrow 94}{77 \rightarrow 93}\right.$ and $\frac{78 \rightarrow 78}{77 \rightarrow 77}$ ) were calculated and corrected for mass bias. Subsequently the $3-\sigma-$ and the $10-\sigma-c r i t e r i o n$ were applied (mean of the blank + (3-times/10-times standard deviation of the blank)) and the results were inserted into the ID equation in order to obtain LOD and LOQ as concentrations. Linearity was investigated with standards containing $0.1-50 \mu \mathrm{g}$ natural $\mathrm{Se} / \mathrm{L}$ and $3 \mu \mathrm{g} / \mathrm{L}{ }^{77} \mathrm{Se}$ in $2 \% \mathrm{HNO}_{3}$. Samples were diluted into this range, if necessary. For method verification, reference materials were analyzed as described above.

\section{Speciation analysis in HepG2 cell lysates by ID-HPLC-ICP-QQQ-MS}

Chromatographic separation of the lysates was carried out with an Agilent 1290 infinity HPLC system (Agilent, Waldbronn, Germany) using a YMC-TriartPFP column ( $3 \mu \mathrm{m}, 3 \times 250 \mathrm{~mm}$, YMC, Dinslaken, Germany) as published before. ${ }^{17}$ As mobile phase $20 \mathrm{mM}$ ammonium formate $(\mathrm{pH} \mathrm{3,3 \%} \mathrm{methanol)} \mathrm{was}$ utilized at a flow rate of $250 \mu \mathrm{L} / \mathrm{min}$ and $30{ }^{\circ} \mathrm{C}$ column temperature. The injected volume comprised $20 \mu \mathrm{L}$. The eluate capillary was coupled online to the ICP-QQQ-MS system via a Tpiece. With another HPLC pump (Merck Hitachi L-6200 A) a 5 $\mu \mathrm{g} / \mathrm{L}{ }^{77} \mathrm{Se}$ spike solution was mixed to the column eluate via this T-piece at a flow rate of $50 \mu \mathrm{L} / \mathrm{min}$ (supplementary figure 1, ESI). ICP-QQQ-MS detection and data analysis were performed as described for total Se determination with the exception that $m / z \frac{78 \rightarrow 94}{77 \rightarrow 93}$ was not used for interference monitoring due to 
comparably low sensitivity. Integration time per $\mathrm{m} / \mathrm{z}$ transition was set to $120 \mathrm{msec}$.

As for total Se data analysis, isotope ratios were calculated and corrected for mass bias for each data point. Subsequently, the chromatogram $f$ (retention time, $\mathrm{min}$ ) = corrected signal intensity (cps) was transformed into the corresponding mass flow chromatograms $f$ (retention time, $\mathrm{min}$ ) = mass flow $\left(\mathrm{ng} / \mathrm{min}\right.$ ) via the online ID equation. ${ }^{27}$ For this purpose, the mass flow of the spike solution was determined by measuring the spike density as well as the spike flow rate conveyed by the additional pump. The exact spike concentration was determined by reverse ID as described above. Supplementary figure 2 (ESI) shows a raw chromatogram of a standard mix containing MeSeCys, TMSe, SeMet and SeSugar 1 in comparison to the corresponding mass flow chromatogram. The peak areas in the mass flow chromatograms were determined by integration with OriginPro software (version 2016G, OriginLab Corporation, Northampton, USA). The species concentration was obtained in $\mathrm{ng} / \mu \mathrm{L}$ by dividing the integrated area $((\mathrm{ng} / \mathrm{min}) * \min =\mathrm{ng})$ by the injected volume $(20 \mu \mathrm{L})$.

LOD and LOQ values for the species-unspecific online ID-HPLCQQQ-MS method were calculated according to the method of Meermann et al. ${ }^{28}$ using three mass flow chromatograms from standard solutions which contained $3 \mu \mathrm{g} \mathrm{Se} / \mathrm{L}$ of the organic Se species. Since the peak width for all species was $1 \mathrm{~min}( \pm 0.1$ min), the average width was determined and applied for integrating the background signal left and right from the peaks. Thus, six background values were obtained, averaged and subsequently the $3-\sigma-$ and $10-\sigma$-criterion were applied as described above. These mass flow values were transformed into concentrations by taking the injected volume into account.

Repeatability was determined as the relative standard deviation of three online ID-HPLC-QQQ-MS measurements of a $6 \mu \mathrm{g} \mathrm{Se/L}$ MeSeCys standard in water and in $50 \%$ cell culture medium, respectively. Recoveries in $50 \%$ cell culture medium, were obtained by spiking with $6 \mu \mathrm{g}$ Se/L per species, measuring and comparing the result to the spiked concentration. Column recovery was investigated with a mixture containing $6 \mu \mathrm{g} \mathrm{Se} / \mathrm{L}$ of MeSeCys, SeMet, TMSe and SeSugar 1, which was analyzed for total Se and Se species. The sum of the Se species concentrations referred to total Se was calculated as column recovery. Linearity was investigated with standard solutions containing concentrations between 1 and $50 \mu \mathrm{g} \mathrm{Se/L} \mathrm{MeSeCys}$ and SeMet. Samples were diluted into this range, if necessary.

\section{HPLC-electrospray-Orbitrap-MS species identification}

For separation and subsequent identification of unknown selenium metabolites a Dionex Ultimate 3000 (Thermo Scientific, Waltham, USA) HPLC system consisting of a Rapid Separation (RS) pump, RS autosampler and RS column compartment was coupled to a $\mathrm{Q}$ Exactive Orbitrap Mass Spectrometer (Thermo Scientific, Waltham, USA) equipped with a heated electrospray ionization (ESI) source from the same manufacturer.

Identification of unknown selenium metabolites was performed after reversed-phase HPLC on a Gemini C6-Phenyl
$(4.6 \times 150 \mathrm{~mm}$; Phenomenex, made in USA) column and its matching guard column (Security Guard cartridge AJ0-7915, Phenomenex). The mobile phase ( $20 \mathrm{mM}$ ammonium formate, $1 \%$ methanol, $\mathrm{pH}$ 9.0) was prepared by dissolving the appropriate amount of ammonium formate in water with $1 \%$ methanol and adjusting the $\mathrm{pH}$ with ammonia solution. Separation was undertaken by isocratic elution at a flow rate of $0.5 \mathrm{~mL} / \mathrm{min}$, a column temperature of $25^{\circ} \mathrm{C}$, and an injection volume of $10 \mu \mathrm{L}$ of a lysate of HepG2 cells treated with $100 \mu \mathrm{M}$ methylselenocysteine for $4 \mathrm{~d}$.

MS was performed in the positive modus and source settings were: gas temperature $435^{\circ} \mathrm{C}$, flow rates 55 (sheath) and 15 (aux) instrument units, spray voltage $3600 \mathrm{~V}$ and capillary temperature $270{ }^{\circ} \mathrm{C}$. The full scan range was $m / z$ 192-700 and a resolution of 35000 (full width half-maximum, FWHM), an automatic gain control (AGC) target of $3 \cdot 10^{6}$, and a maximum injection time (IT) of $100 \mathrm{~ms}$ were used. MS/MS (ddMS/MS) for the precursor ions at $\mathrm{m} / \mathrm{z} 313$ and 370 was performed after recording of full scans. Collision energies of 30 and 20-25 (stepped) instrument units were used for the MS/MS experiments for $m / z 313$ and 370 , respectively. MS/MS settings were: maximum injection time $50 \mathrm{msec}$, AGC $2 \cdot 10^{5}$, resolution 17500 FWHM. An isolation window of 10 Thomson (charge/mass) was used.

\section{Results and discussion}

\section{Development and validation of an ID ICP-QQQ-MS method for} total Se and a post-column species-unspecific online ID-HPLC-ICPQQQ-MS method for speciation analysis

For quantifying total Se and small Se species in the cell samples, two ID ICP-QQQ-MS-based methods were developed. Spectral interferences were minimized by applying a triple-quadrupole instrument and by measuring Se with a mixture of hydrogen and oxygen in the reaction and collision cell (CRC). The most abundant Se isotopes were detected on mass and in mass shift mode as their oxygen products $(+m / z 16)$, allowing for elucidation of potential spectral interferences by comparing the results for the different $\mathrm{m} / \mathrm{z} .{ }^{17}$ Non-spectral interferences were compensated by ID, whereby an isotope of the analyte element undergoing the same ionization conditions in the plasma and possessing the same chemical properties was used for quantification as spike. ${ }^{29,30}$

For the determination of total Se a ${ }^{77}$ Se spike was added to the samples prior to sample preparation. This offered the advantage of compensating potential sample losses as well as for inaccuracies of the microwave-assisted acid digestion procedure, which was necessary in case of the residues from cell lysis as they did not represent homogenous solutions. The cell lysates were not subjected to microwave-assisted acid digestion as they were homogenous, clear solutions and ID analysis enables measurement of non-digested samples as long as all Se species present in the sample respond equally during ICP-MS detection. ${ }^{31}$ For speciation analysis, online post-column species-unspecific ID was chosen as quantification method, 
because it allows to quantify also unknown species and it is able to compensate for drift effects during measurement. ${ }^{27}$ The suitability of this approach was recently highlighted by the quantification of MeSeCys, SeMet and SeSugar 1 in human serum. ${ }^{32}$

In table 1 , basic characteristics of the developed methods are summarized. LOD and LOQ for total Se by ID ICP-QQQ-MS were in the range of recently published ICP-QQQ-MS methods. ${ }^{33,34}$ Recoveries for certified fish material as well as for control serum demonstrate high accuracy. Regarding the ID-HPLC-ICP-QQQMS method, LODs and LOQs are in accordance with recently published results. ${ }^{32}$ With a relative standard deviation between 4 and $7 \%$ in water as well as 6 to $8 \%$ in matrix, repeatability was evaluated as satisfactory. As well column recovery and the recovery of the respective standards in $50 \%$ cell culture medium proved to be quantitative.

\section{Cytotoxicity and total cellular Se in HepG2 cells}

As this study aimed to elucidate the extent of cytotoxic effects in relation to the aforementioned species and potentially formed metabolites, incubation concentrations inducing significant effects were chosen. For cytotoxicity testing, the cell number of the incubated HepG2 cells was counted prior to Se analysis. The corresponding cytotoxicity curves (figure 1) are in line with our previously published cytotoxicity data in HepG2 cells after $48 \mathrm{~h}$ of incubation. ${ }^{17}$ Generally, strong speciesspecific effects were obtained in a time- and concentration dependent manner.

Approximately equal effects were obtained following $100 \mu \mathrm{M}$ incubation with MeSeCys and $150 \mu \mathrm{M}$ incubation with SeMet (figure $1 \mathrm{~A}$ and $1 \mathrm{~B}$ ) demonstrating that their cytotoxic effects are in the same order of magnitude. Similar cytotoxic effects of MeSeCys and SeMet were shown for other cell lines and endpoints before, with MeSeCys exhibiting slightly stronger effects in most cases. ${ }^{17,35,36}$ However, at these incubation concentrations, SeMet induced depending on the incubation time 23- till 45-fold higher total cellular Se than MeSeCys. Thus, despite being similarly toxic, total Se concentration in the HepG2 cells substantially deviated between MeSeCys and SeMet pointing to species-specific effects. Incubation with 150 and $200 \mu \mathrm{M}$ SeMet resulted in no significant difference in total cellular Se concentrations (figure 1B) indicating that high SeMet supply might lead to a saturation in HepG2 cells.

For TMSe and SeSugar 1 one concentration was investigated following $4 \mathrm{~d}$ of incubation in order to ensure the absence of

Table 1: Characteristics of the optimized ID ICP-QQQ-MS and ID-HPLC-ICP-QQQ-MS methods for the validated mass to charge transitions ( $m / z$ ). Limits of detection (LOD) and limits of quantification (LOQ) were calculated according to the 3- $\sigma$ - and $10-\sigma-c r i t e r i o n$, respectively. Relative standard deviation (RSD) and standard deviation (SD) were calculated from at least three independent determinations. Correlation coefficients indicate the linearity within the investigated concentration range by using ID analysis.

\begin{tabular}{|c|c|c|c|c|}
\hline ID ICP-QQQ-MS method & $\begin{array}{c}\text { Certified/ } \\
\text { reference } \\
\text { concentration }\end{array}$ & $m / z \frac{78 \rightarrow 78}{77 \rightarrow 77}$ & $m / z \frac{80 \rightarrow 80}{77 \rightarrow 77}$ & $m / z \frac{80 \rightarrow 96}{77 \rightarrow 93}$ \\
\hline $\mathrm{LOD}(\mu \mathrm{g} / \mathrm{L})$ & & 0.028 & 0.044 & 0.011 \\
\hline $\mathrm{LOQ}(\mu \mathrm{g} / \mathrm{L})$ & & 0.092 & 0.165 & 0.032 \\
\hline Total Se in certified fish muscle ERM ${ }^{\oplus}-B B 422 \pm S D[\mathrm{mg} / \mathrm{kg}](\mathrm{n}=7)$ & $1.33 \pm 0.13$ & $1.30 \pm 0.08$ & $1.31 \pm 0.08$ & $1.31 \pm 0.06$ \\
\hline $\begin{array}{l}\text { Total Se in reference Clinchek }{ }^{\infty} \text { control serum } \\
\text { Level I } \pm \text { SD without digestion }[\mu \mathrm{g} / \mathrm{L}](\mathrm{n}=3)\end{array}$ & $66.1 \pm 13.2$ & $69.1 \pm 0.9$ & $68.8 \pm 2.4$ & $68.0 \pm 0.2$ \\
\hline $\begin{array}{l}\text { Total Se in reference Clinchek }{ }^{*} \text { control serum Level II } \pm \text { SD } \\
\text { without digestion }[\mu \mathrm{g} / \mathrm{L}](\mathrm{n}=3)\end{array}$ & $105 \pm 21$ & $103.3 \pm 3.0$ & $102.4 \pm 3.4$ & $101.2 \pm 3.4$ \\
\hline Investigated linear range $[\mu \mathrm{g} / \mathrm{L}]$ & $0.1-50$ & & & \\
\hline Correlation coefficient & & 0.9998 & 0.9996 & 0.9998 \\
\hline ID-HPLC-ICP-QQQ-MS method & $\begin{array}{c}\text { Spiked } \\
\text { concentration }\end{array}$ & $m / z \frac{78 \rightarrow 78}{77 \rightarrow 77}$ & $m / z \frac{80 \rightarrow 80}{77 \rightarrow 77}$ & $m / z \frac{80 \rightarrow 96}{77 \rightarrow 93}$ \\
\hline $\operatorname{LOD}[\mu \mathrm{g} / \mathrm{L}]$ & & 0.47 & 0.45 & 0.34 \\
\hline LOQ $[\mu \mathrm{g} / \mathrm{L}]$ & & 0.77 & 0.67 & 0.60 \\
\hline Repeatability of MeSeCys in water $(n=3)$ & $6.0 \mu \mathrm{g} \mathrm{Se} / \mathrm{L}$ & 4.6 RSD\% & $6.5 \mathrm{RSD} \%$ & 6.5 RSD\% \\
\hline Repeatability of MeSeCys in $50 \%$ cell culture medium $(n=3)$ & $6.0 \mu \mathrm{g} \mathrm{Se} / \mathrm{L}$ & 7.7 RSD\% & $7.2 \mathrm{RSD} \%$ & 6.7 RSD\% \\
\hline Recovery in $50 \%$ cell culture medium \pm SD [\%] $(n=3)$ & $6.0 \mu \mathrm{g} \mathrm{Se} / \mathrm{L}$ & & & \\
\hline MeSeCys & & $102.6 \pm 7.7$ & $98.1 \pm 7.2$ & $98.8 \pm 6.7$ \\
\hline TMSe & & $100.7 \pm 7.5$ & $103.6 \pm 4.7$ & $101.5 \pm 5.3$ \\
\hline SeMet & & $104.9 \pm 3.4$ & $103.9 \pm 4.7$ & $105.8 \pm 5.6$ \\
\hline SeSugar 1 & & $106.9 \pm 2.8$ & $107.3 \pm 3.8$ & $105.1 \pm 8.6$ \\
\hline Column recovery \pm SD $[\%](n=3)$ & $\begin{array}{l}6.0 \mu \mathrm{g} \mathrm{Se} / \mathrm{L} \\
\text { per species }\end{array}$ & $101.3 \pm 4.3$ & $96.8 \pm 3.6$ & $103.8 \pm 3.7$ \\
\hline Investigated linear range $(\mu \mathrm{g} / \mathrm{L})$ & $1-50$ & & & \\
\hline Correlation coefficient & & 0.9998 & 0.9999 & 0.9997 \\
\hline
\end{tabular}



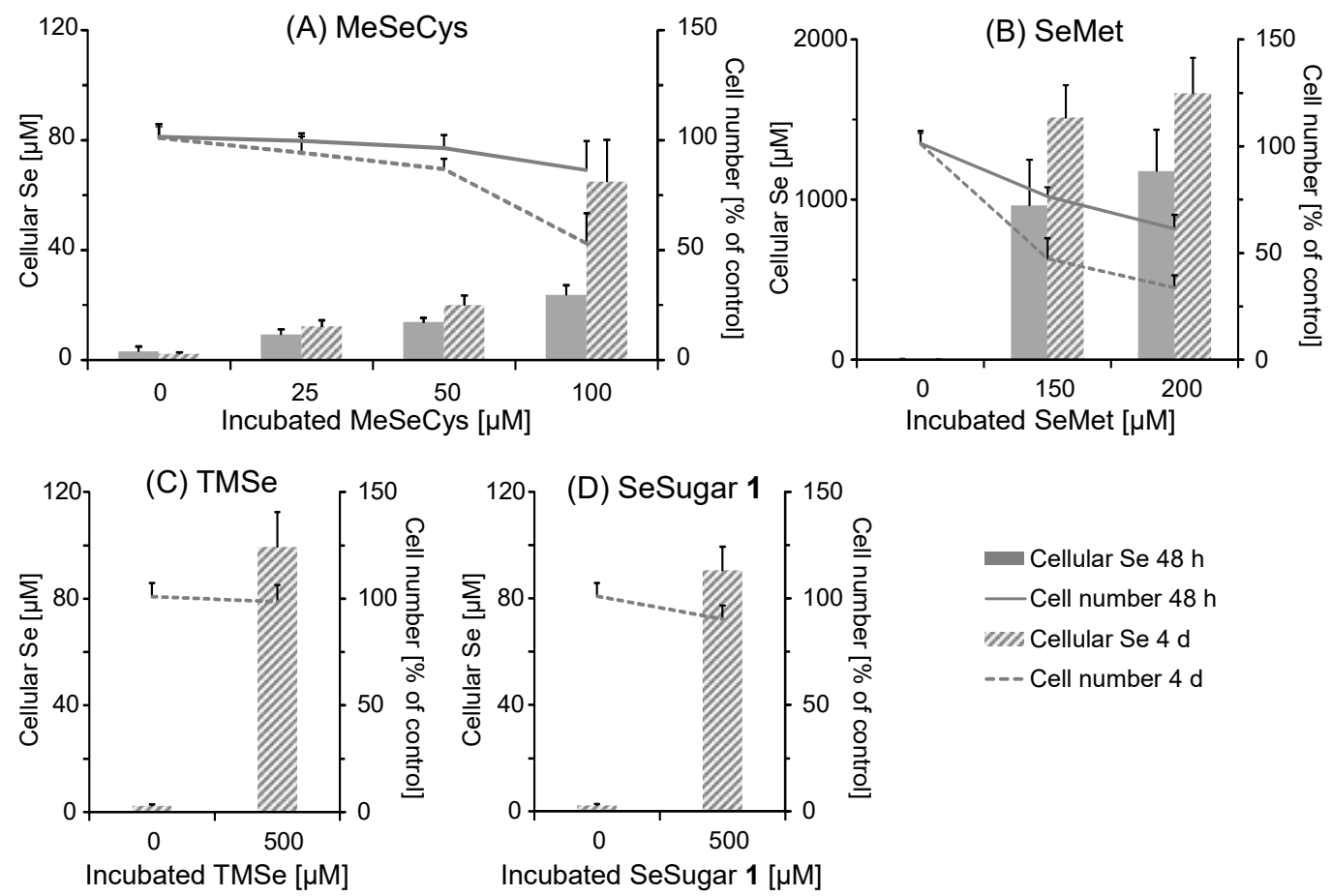

Figure 1: Total cellular Se (left axis) in comparison to cytotoxic effects as assessed by cell number (right axis) of HepG2 cells incubated for $48 \mathrm{~h}$ and $4 \mathrm{~d}$ with MeSeCys (A), SeMet (B), TMSe (C) and SeSugar 1 (D). Shown are mean values of at least three independent determinations + SD.

toxic effects after a long incubation period. Both species were non-toxic up to $500 \mu \mathrm{M}$ as previously published ${ }^{17,37}$ despite high total cellular Se concentrations in the HepG2 cells (figure 1C, D). Total cellular Se was in the same order of magnitude as after $100 \mu \mathrm{M}$ MeSeCys incubation. On the one hand, this indicates that TMSe and SeSugar 1 are much less bioaccessible, because less than $1 / 5$ of the applied Se (as Se species) was detected in the cells. On the other hand similar total cellular Se concentrations following TMSe and SeSugar 1 incubation did not result in comparable cytotoxicity as for MeSeCys, again pointing to species-specific effects.

Consequently, as reported for urothelial, prostate cancer, colon cancer and leukemia cells, ${ }^{16,17}$ no direct inter-species correlation between total cellular Se and cytotoxic effects was found for the investigated species in HepG2 cells.

\section{Cellular transformations of small Se species in HepG2 cells}

In order to explore possible reasons for the distinct differences of the cytotoxic effects of the Se compounds, ID-HPLC-ICP-QQQMS was applied to measure small Se species in the cells (figure 2). Regarding SeSugar 1 and TMSe, both species were detected in the cell lysates in an unmodified manner. When comparing their concentrations to total cellular Se, nearly quantitative recoveries ( $89 \%$ and $94 \%$ respectively, table 2 ) were obtained. This shows that the urinary metabolites are not significantly metabolized and they do not seem to be incorporated by the cells.

After SeMet incubation, two species were present in the lysates in addition to SeMet (figure 2C). As described earlier, the first peak is likely to be oxidized SeMet (SeOMet), a sample preparation artifact. ${ }^{16,17}$ Moreover a less polar Se containing substance with unknown identity eluted later in the chromatogram (figure $2 \mathrm{C}$ ). This species had not been previously detected in urothelial cells, suggesting tissue-dependent variability. Both concentrations of SeOMet and unknown species III increased proportionally with the cellular concentration of SeMet in a time-dependent manner (table 2) and it remains debatable if they are involved in the cytotoxic mechanisms of SeMet. Since SeOMet might have been formed during sample preparation, it is less likely to be involved in the cellular processes. Cytotoxic effects of high SeMet concentrations might also be a consequence of structural protein deformations, if Se excessively replaces sulfur in methionines. ${ }^{9}$ Even though small Se species increased, total cellular Se seemed to undergo saturation. This indicates, that HepG2 cells might be able to partly down regulate Se incorporation.

In the lysates of cells treated with MeSeCys, the incubated species was detected in its intact form. Likewise, Suzuki et al. found in rat organs, that MeSeCys was taken up in an unmodified manner. ${ }^{11}$ Moreover, two further Se species were present in the lysates, which did not match any of our reference substances regarding their retention times (figure $2 \mathrm{~B}, \mathrm{I}$ and II). The amount of all three Se species increased with incubation concentration and time and a maximum was obtained following $4 \mathrm{~d}$ of incubation with $100 \mu \mathrm{M}$ MeSeCys (table 2). To exclude that the unknown Se compounds originated from sample preparation, control cell pellets were spiked with MeSeCys prior and after sonication with and without $30 \mathrm{~min}$ resting time. Since HPLC-ICP-QQQ-MS analysis did not reveal any additional species apart from MeSeCys (data not shown), we concluded that both unknown species originated from inherent cellular 


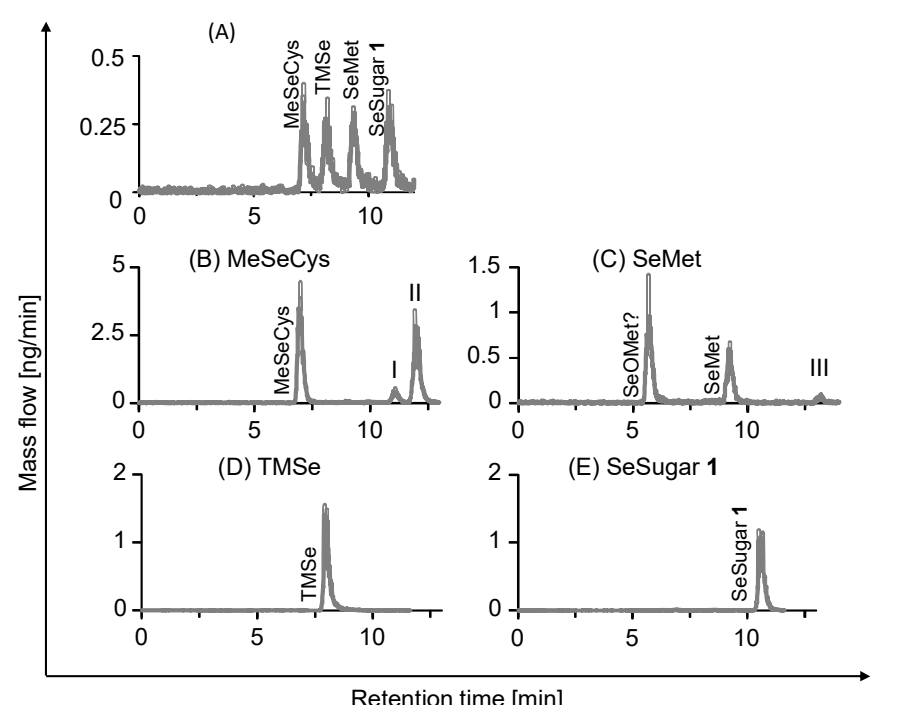

Figure 2: RP-HPLC-ICP-QQQ-MS mass flow chromatograms of a $5 \mu \mathrm{g} / \mathrm{L}$ standard mix (A) and the HepG2 cell lysates incubated for $4 \mathrm{~d}$ with $100 \mu \mathrm{M}$ MeSeCys (B),

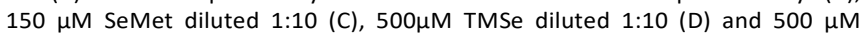
SeSugar 1 diluted 1:10 (E). Unknown peaks are marked with I - III. Chromatographic separation was performed on a YMC-TriartPFP column $(3 \mu \mathrm{m}$ $3 \times 250 \mathrm{~mm})$ at $30{ }^{\circ} \mathrm{C}$ with $250 \mu \mathrm{L} / \mathrm{min} 20 \mathrm{mM}$ ammonium formate $(\mathrm{pH} 3,3 \%$ methanol) as mobile phase. $m / z \frac{80 \rightarrow 96}{77 \rightarrow 93}$

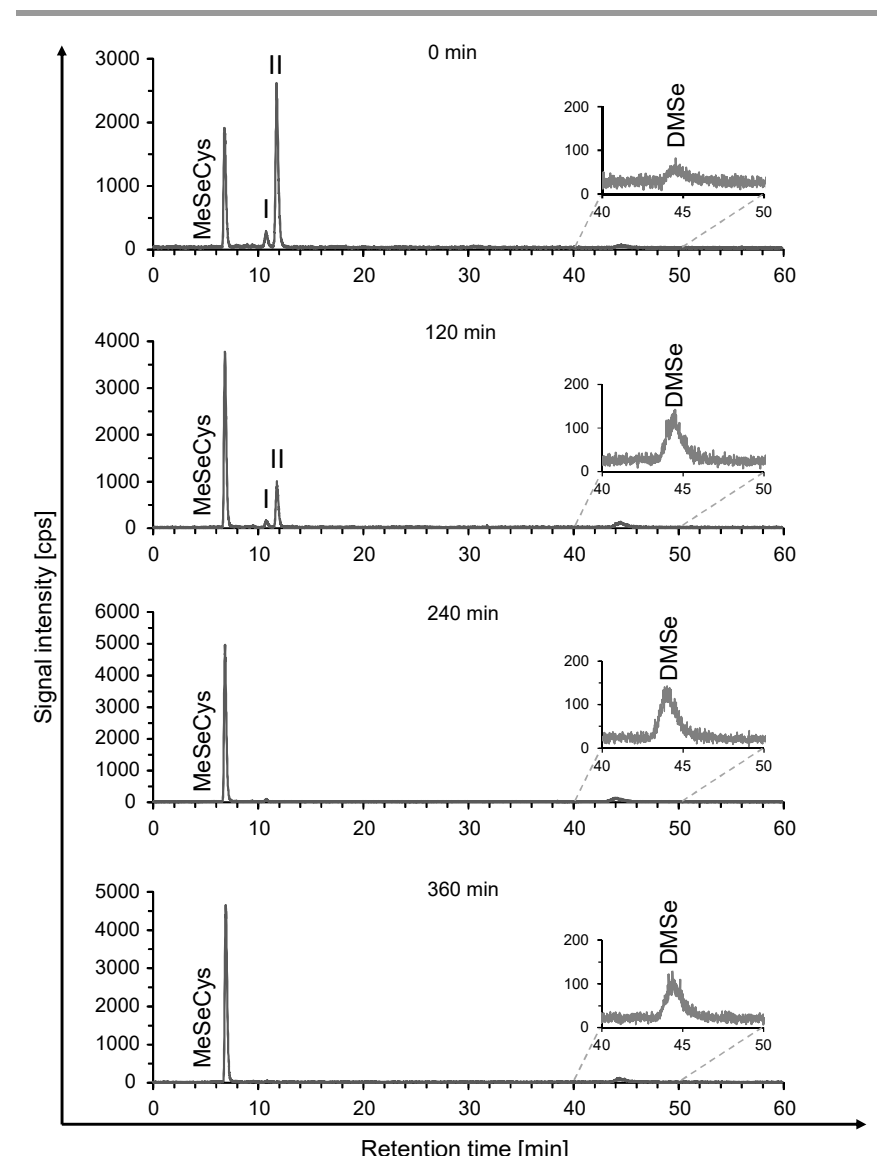

Figure 3: HPLC-ICP-QQQ-MS raw chromatograms of a HepG2 lysate, which was incubated with $50 \mu \mathrm{M}$ MeSeCys for $4 \mathrm{~d}$ and directly injected every $120 \mathrm{~min}$ without cooling between the runs. Each run took $120 \mathrm{~min}$, but to improve readability the chromatograms are only shown up to $60 \mathrm{~min}$ because no additional species was detected. Unknown species are marked with I and II, DMSe: dimethylselenide. $m / z 80 \rightarrow 80$ processes. Interestingly, unknown species I was only detected in cytotoxic incubation concentrations above the LOQ. Moreover, in comparison to MeSeCys, it increased overproportionally in its cellular concentration in contrast to unknown species II. This might suggest that unknown species I is involved in cytotoxic damage, either as a cause or as a consequence. So far, no other group detected these unknown metabolites of MeSeCys, most likely due to lower incubation concentration as those studies aimed to elucidate metabolic pathways under physiological conditions instead of cytotoxic characteristics. ${ }^{16,21,38}$ Unknown species I and II were also detected in urothelial cells at cytotoxic incubation concentrations of MeSeCys indicating that the metabolites might be relevant for several cellular systems. ${ }^{17}$ Furthermore, a small amount of volatile dimethylselenide (DMSe) was detected in the MeSeCys lysates after $120 \mathrm{~min}$ of storage at room temperature and increased with storage time (figure 3 ). Volatile species were detected as well in other cell lines like lymphoma cells and rat hepatocytes following MeSeA incubation. ${ }^{39,40}$ DMSe might compromise total selenium determination as it is known to have higher response in the ICP-MS compared to other selenium species due to its higher volatility. ${ }^{31}$ As our lysates were stored at $-20^{\circ} \mathrm{C}$ until analysis of total Se, formation of DMSe was kept low and thus, it is unlikely that DMSe contributed significantly to total Se determined by ID ICP-QQQMS.

When comparing the sum of MeSeCys and unknown species I and II to total cellular Se in the MeSeCys pellets, between 29 and $62 \%$ of cellular Se were present in the lysates as small Se species. Most likely, the remaining Se was incorporated into proteins. In contrast, following SeMet incubation, only about $10 \%$ of total cellular Se was present as small Se species (table 2 and supplementary table 3 ). This difference indicates that SeMet was used much more efficiently by the HepG2 cells than MeSeCys, either for specific or unspecific incorporation into selenoproteins.

\section{Identification of MeSeCys metabolites}

As MeSeCys is of particular interest as a potential anti-cancer agent, we focused on the identification of its two detected metabolites. MeSeCys incubation was discussed to lead to the formation of $\mathrm{MeSeH}$, which is discussed to mediate anti-cancer properties of MeSeCys in vitro and in vivo. ${ }^{11,12,16}$ However, this metabolite is highly reactive and not likely detectable without derivatization. Consequently, it was excluded that one of the unknown MeSeCys metabolites was MeSeH. Weekley et al. showed diselenide formation in human neuroblastoma cells following MeSeCys incubation by means of x-ray absorption near edge spectroscopy. ${ }^{15}$ Repeated analysis of MeSeCys lysates revealed that both unknown species were not stable during sample storage at room temperature, with decelerated degradations at $4{ }^{\circ} \mathrm{C}$ and $-20{ }^{\circ} \mathrm{C}$. A systematic investigation showed that they completely degraded at room temperature with concomitant quantitative regeneration of MeSeCys (figure 3 and supplementary table 2, ESI). This indicated that MeSeCys 
Table 2: Small Se species in HepG2 lysates as quantified by ID-HPLC-ICP-QQQ-MS in comparison to the cytotoxic effects as quantified by cell number counting following $48 \mathrm{~h}$ and $4 \mathrm{~d}$ of incubation, respectively. Shown are mean values of at least three independent determinations \pm standard deviations. $n$. d.: not detectable; $n$. q.: not quantifiable

\begin{tabular}{|c|c|c|c|c|c|c|c|c|c|c|}
\hline \multirow{2}{*}{$\begin{array}{c}\text { Incubated } \\
\text { MeSeCys } \\
{[\mu \mathrm{M}]}\end{array}$} & \multicolumn{2}{|c|}{$\begin{array}{c}\text { Cellular MeSeCys } \\
{[\mu \mathrm{M}]}\end{array}$} & \multicolumn{2}{|c|}{$\begin{array}{l}\text { Cellular unknown } \\
\qquad[\mu \mathrm{M}]\end{array}$} & \multicolumn{2}{|c|}{$\begin{array}{c}\text { Cellular unknown } \\
\quad \text { II }[\mu \mathrm{M}]\end{array}$} & \multicolumn{2}{|c|}{$\begin{array}{l}\text { Cell number } \\
{[\% \text { of control] }}\end{array}$} & \multicolumn{2}{|c|}{$\begin{array}{l}\text { Sum of small species } \\
\text { [\% of total cellular Se] }\end{array}$} \\
\hline & $48 \mathrm{~h}$ & $4 \mathrm{~d}$ & $48 \mathrm{~h}$ & $4 d$ & $48 \mathrm{~h}$ & $4 d$ & $48 \mathrm{~h}$ & $4 \mathrm{~d}$ & $48 \mathrm{~h}$ & $4 \mathrm{~d}$ \\
\hline 25 & $1.2 \pm 0.2$ & $2.7 \pm 1.0$ & n. d. & n. q. & $1.4 \pm 0.7$ & $2.2 \pm 1.1$ & $99.6 \pm 2.1$ & $94.3 \pm 8.8$ & 29 & 40 \\
\hline 50 & $2.5 \pm 0.5$ & $4.0 \pm 1.2$ & n. q. & $0.5 \pm 0.2$ & $2.5 \pm 1.0$ & $3.9 \pm 1.7$ & $96.3 \pm 6.0$ & $86.8 \pm 4.8$ & 36 & 42 \\
\hline 100 & $3.8 \pm 1.0$ & $17.5 \pm 4.2$ & $0.5 \pm 0.1$ & $3.9 \pm 1.9$ & $3.3 \pm 0.7$ & $19.0 \pm 3.7$ & $86 \pm 13$ & $53 \pm 14$ & 32 & 62 \\
\hline $\begin{array}{l}\text { Incubated } \\
\text { SeMet }\end{array}$ & \multicolumn{2}{|c|}{$\begin{array}{c}\text { Cellular SeOMet? } \\
{[\mu \mathrm{M}]}\end{array}$} & \multicolumn{2}{|c|}{$\begin{array}{c}\text { Cellular SeMet } \\
{[\mu \mathrm{M}]}\end{array}$} & \multicolumn{2}{|c|}{$\begin{array}{c}\text { Cellular unknown III } \\
{[\mu \mathrm{M}]}\end{array}$} & \multicolumn{2}{|c|}{$\begin{array}{l}\text { Cell number } \\
{[\% \text { of control] }}\end{array}$} & \multicolumn{2}{|c|}{$\begin{array}{l}\text { Sum of small species } \\
\text { [\% of total cellular Se] }\end{array}$} \\
\hline$[\mu \mathrm{M}]$ & $48 \mathrm{~h}$ & $4 d$ & $48 \mathrm{~h}$ & $4 \mathrm{~d}$ & $48 \mathrm{~h}$ & $4 \mathrm{~d}$ & $48 \mathrm{~h}$ & $\begin{array}{l:l}\mathrm{d} \\
\end{array}$ & $48 \mathrm{~h}$ & $4 \mathrm{~d}$ \\
\hline 150 & $56 \pm 15$ & $110 \pm 19$ & $25.4 \pm 3.5$ & $43.0 \pm 8.8$ & $7.1 \pm 2.2$ & $8.8 \pm 2.0$ & $76.3 \pm 4.5$ & $47.3 \pm 9.6$ & 9 & 10 \\
\hline 200 & $87 \pm 15$ & $137 \pm 30$ & $40.1 \pm 8.8$ & $78 \pm 16$ & $9.9 \pm 1.6$ & $13.7 \pm 2.8$ & $61.3 \pm 6.5$ & $33.6 \pm 5.8$ & 13 & 14 \\
\hline \multirow[t]{2}{*}{$\begin{array}{c}\text { Incubated } \\
\text { TMSe } \\
{[\mu \mathrm{M}]}\end{array}$} & $\begin{array}{l}\text { Cellular } \\
\text { TMSe } \\
{[\mu \mathrm{M}]}\end{array}$ & $\begin{array}{c}\text { Cell number } \\
\text { [\% of } \\
\text { control] }\end{array}$ & \multicolumn{2}{|c|}{$\begin{array}{c}\text { Sum of small species } \\
\text { [\% of total cellular Se] }\end{array}$} & $\begin{array}{c}\text { Incubated } \\
\text { SeSugar } 1 \\
{[\mu \mathrm{M}]}\end{array}$ & \multicolumn{2}{|c|}{$\begin{array}{c}\text { Cellular SeSugar } 1 \\
{[\mu \mathrm{M}]}\end{array}$} & $\begin{array}{l}\text { Cell number } \\
\text { [\% of control] }\end{array}$ & \multicolumn{2}{|c|}{$\begin{array}{l}\text { Sum of small species } \\
{[\% \text { of total cellular Se] }}\end{array}$} \\
\hline & $4 d$ & $4 d$ & \multicolumn{2}{|c|}{$4 d$} & & \multicolumn{2}{|c|}{$4 d$} & $4 \mathrm{~d}$ & \multicolumn{2}{|c|}{$4 d$} \\
\hline $500 \mu \mathrm{M}$ & $93 \pm 30$ & $98.5 \pm 7.8$ & \multicolumn{2}{|c|}{94} & $500 \mu \mathrm{M}$ & \multicolumn{2}{|c|}{$80.3 \pm 7.5$} & $90.3 \pm 6.4$ & \multicolumn{2}{|c|}{89} \\
\hline
\end{tabular}

might be bound intact to other structures and was released again during storage negating the formation of a diselenide. In order to clarify the identity of the metabolites, HPLC-ESIOrbitrap-MS experiments were performed. The high resolution full scan spectrum of a lysate of HepG2 cells treated with 100 $\mu \mathrm{M}$ MeSeCys for $4 \mathrm{~d}$ showed a characteristic isotopic pattern of Se (pseudo-molecular ion $[\mathrm{M}+\mathrm{H}]^{+}: \mathrm{m} / \mathrm{z} 313.0302$ for ${ }^{80} \mathrm{Se}$ ) at the

(A)

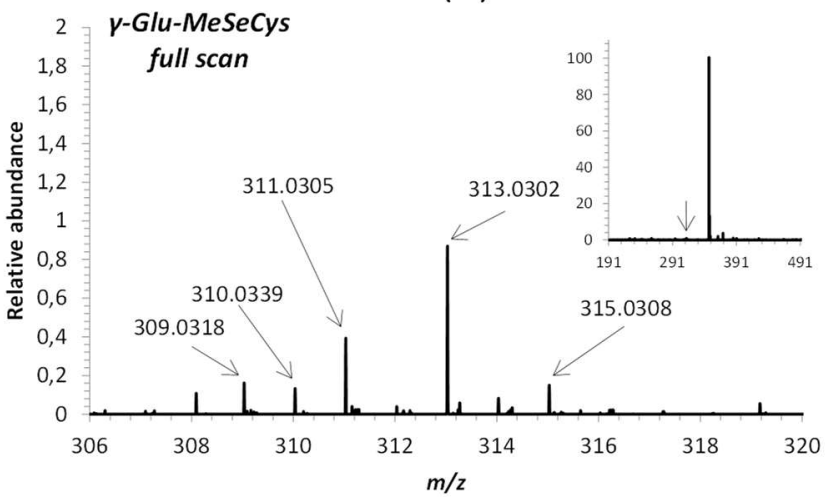

(C)

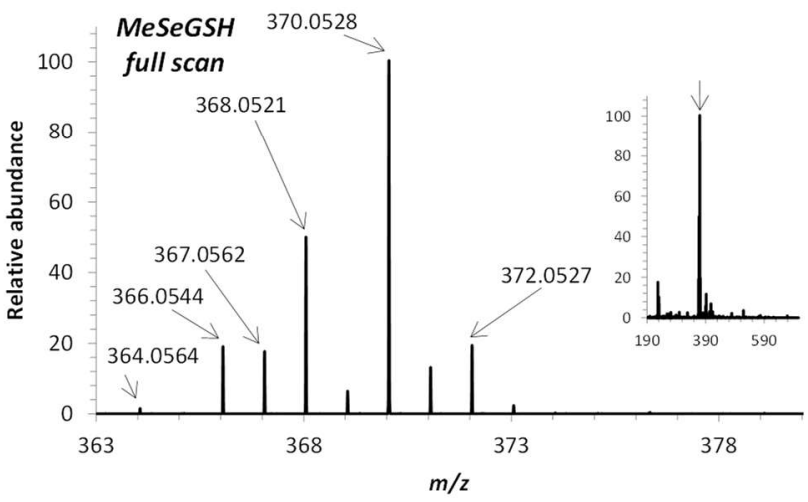

(B)

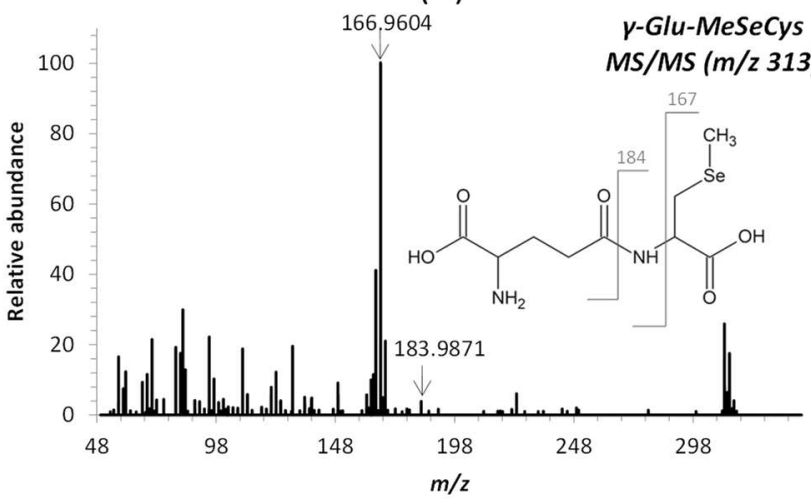

(D)

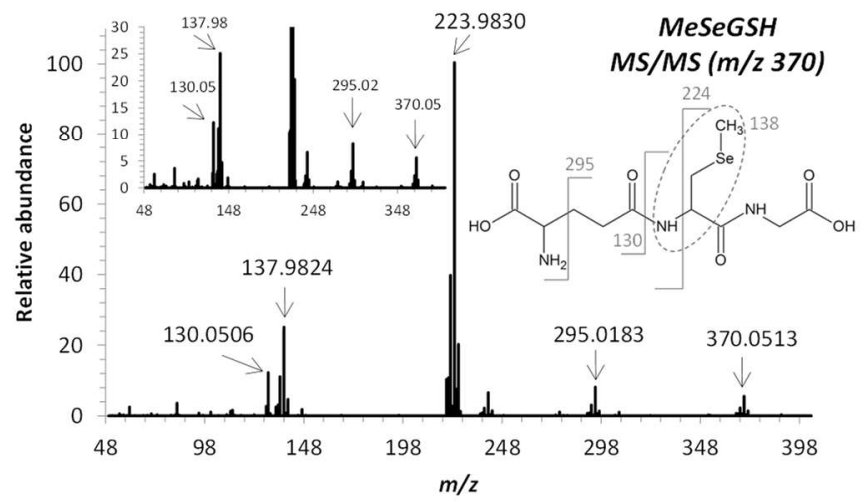

Figure 4: Identification of $\mathrm{Y}$-Glu-MeSeCys (A, B) and MeSeGSH (C, D) via the isotopic pattern of Se (A, C) and their fragmentation products (B, D) applying HPLC-ESIOrbitrap-MS analysis in a HepG2 lysate following $4 \mathrm{~d}$ of incubation with $100 \mu \mathrm{M}$ MeSeCys. 
unknown species II was identified as Se-methylselenoglutathione (MeSeGSH; figure $4 \mathrm{C}$ and D) via its characteristic isotopic Se pattern, its exact mass (calculated pseudo-molecular ion $[\mathrm{M}+\mathrm{H}]^{+}: \quad \mathrm{m} / \mathrm{z} 370.0519$ for ${ }^{80} \mathrm{Se}$ ) and the typical fragmentation described in the literature. ${ }^{41,42}$

$\gamma$-Glu-MeSeCys is a Se metabolite in Allium plants and thus, it is a component of our diet. ${ }^{43}$ In vitro experiments suggested, that it loses its glutamyl moiety during gastric digestion, ${ }^{44}$ which most likely also happened during the storage of the HepG2 lysates. Moreover $\mathrm{Y}$-Glu-MeSeCys was shown to be a metabolite of methylselenic acid (MeSeA) along with MeSeCys and SeMet in human lymphoma cells ${ }^{39}$ indicating that MeSeA is metabolized via MeSeCys to $\mathrm{Y}$-Glu-MeSeCys. So far, there are no data on the cytotoxicity of $\mathrm{y}$-Glu-MeSeCys available. Consequently, it remains uncertain, if it is a detoxification product of Se metabolism (like in plants) or rather similarly toxic as its metabolite MeSeCys since it is able to release $\mathrm{MeSeH}$ as well. ${ }^{43}$ In contrast to $\gamma$-Glu-MeSeCys, MeSeGSH has not been detected in human cells before, although it was repeatedly detected in selenium-rich yeast. ${ }^{41,42}$ Also the meaning of MeSeGSH being present under cytotoxic conditions in HepG2 cells remains unclear, because nothing is known about its possible cytotoxic effects. As described earlier quantitative speciation results indicated, that cellular $y$-Glu-MeSeCys concentrations increased with cytotoxicity in an overproportional manner. This may indicate that $\gamma$-GluMeSeCys could have contributed to the cytotoxic effects of MeSeCys in HepG2 cells.

\section{Concluding remarks}

The developed procedure based on cell number counting and ID(-HPLC-)ICP-QQQ-MS allowed to quantify three parameters in the same HepG2 cell pellet following incubation with the investigated organic Se species: The cytotoxic effects, total cellular Se and organic small Se species. Using this approach strongly species-dependent total cellular Se concentrations were obtained (SeMet $>$ MeSeCys $\approx$ TMSe $\approx$ SeSugar 1 ) which were not directly decisive for the cytotoxic effects (MeSeCys > SeMet > TMSe, SeSugar 1). Here, quantitative speciation analysis provided additional hints on the underlying mechanisms.

Our data provide evidence, that the two major human Se excretion metabolites TMSe and SeSugar 1 are not further metabolized in the HepG2 cells, as their cellular species concentrations were nearly equal to the corresponding total cellular Se. This might explain why they were not toxic up to 500 $\mu \mathrm{M}$ in the HepG2 cells. To our knowledge TMSe and SeSugar 1 have not been investigated regarding their metabolism in liver cells before. As in the SeMet lysates no particular species could be linked to the cytotoxic effects of SeMet, excessive unspecific SeMet incorporation in places of methionine might have affected protein functions. Comparing total Se and the sum of small Se species, only about $10 \%$ of total cellular Se was present as small species indicating that the "missing" part was accumulated in proteins. In contrast, MeSeCys was used less efficiently by the cells (about 50\%). For the first time, two metabolites of MeSeCys were found in human liver cells under cytotoxic conditions. They were identified by means of HPLCESI-Orbitrap-MS as $\gamma$-glutamyl-MeSeCys and MeSeGSH. Since their effects on human cells have not been tested yet, their function remains unclear. $v$-glutamyl-MeSeCys was only quantifiable in cytotoxic concentrations and as it is discussed to exhibit anti-cancer activity, it could have contributed to the cytotoxic effects of MeSeCys in the hepatoma cell line. Here, further studies are needed to better understand the species transformations and cytotoxic actions of MeSeCys and its metabolites.

\section{Acknowledgements}

We thank the "Fonds der Chemischen Industrie", the "Deutsche Forschungsgemeinschaft" (DFG, project grant number SCHW 903/9-1) and the Austrian Science Fonds (FWF, I 2262-N28) as well as the "NutriAct - Competence Cluster Nutrition Research Berlin-Potsdam" funded by the Federal Ministry of Education and Research (project number 01EA1408B) for financial support. Moreover, we would like to thank Professor Dr. K. A. Francesconi for providing the reference substances TMSe and SeSugar 1.

The authors have declared no conflicts of interest.

\section{References}

1 Scientific Committee on Food, Opinion of the Scientific Committee on Food on the Tolerable Upper Intake Level of Selenium, Brussel, 2000.

2 J. K. Wrobel, R. Power and M. Toborek, IUBMB Life, 2016, 68, 97-105.

3 E. Jablonska and M. Vinceti, J. Environ. Sci. Heal. Part CEnvironmental Carcinog. Ecotoxicol. Rev., 2015, 33, 328368.

4 A. P. Kipp, D. Strohm, R. Brigelius-Flohé, L. Schomburg, A. Bechthold, E. Leschik-Bonnet and H. Heseker, J. Trace Elem. Med. Biol., 2015, 32, 195-199.

5 B. Gammelgaard, M. I. Jackson and C. Gabel-Jensen, Anal. Bioanal. Chem., 2011, 399, 1743-1763.

6 C. M. Weekley and H. H. Harris, Chem. Soc. Rev., 2013, 42, 8870-8894.

7 M. P. Rayman, H. Goenaga Infante and M. Sargent, Br. J. Nutr., 2008, 100, 238-253.

8 E. Dumont, F. Vanhaecke and R. Cornelis, Anal. Bioanal. Chem., 2006, 385, 1304-1323.

9 G. N. Schrauzer, Adv. Food Nutr. Res., 2003, 47, 73-112.

10 F. Aguilar, U. R. Charrondiere, B. Dusemund, P. Galtier, J. Gilbert, D. M. Gott, S. Grilli, R. Guertler, G. E. N. Kass, J. Koenig, C. Lambré, J.-C. Larsen, J.-C. Leblanc, A. Mortensen, D. Parent-Massin, I. Pratt, I. M. C. M. Rietjens, I. Stankovic, P. T. Tobback and R. Woutersen, EFSA J., 2009, 1067, 1-23.

11 K. T. Suzuki, Y. Tsuji, Y. Ohta and N. Suzuki, Toxicol. Appl. Pharmacol., 2008, 227, 76-83.

12 C. Gabel-Jensen, K. Lunøe and B. Gammelgaard, Metallomics, 2010, 2, 167-173.

13 Directive 2002/46/EC of the European Parliament and the 
Council of 10 June 2002 on the approximation of the laws of the member states relating to food supplements, 2015, $1-16$.

D. Kuehnelt, K. Engström, H. Skröder, S. Kokarnig, C. Schlebusch, M. Kippler, A. Alhamdow, B. Nermell, K. A. Francesconi, K. Broberg and M. Vahter, Am. Clin. Nutr., 2015, 102, 1406-1415.

C. M. Weekley, J. B. Aitken, I. F. Musgrave and H. H. Harris, Biochemistry, 2012, 51, 736-738. and B. Gammelgaard, Metallomics, 2011, 3, 162-168. . A. Marschall, J. Bornhorst, D. Kuehnelt and T. Schwerdtle, Mol. Nutr. Food Res., 2016, 1-12.

S. Kokarnig, A. Tsirigotaki, T. Wiesenhofer, V. Lackner, K. A. Francesconi, S. A. Pergantis and D. Kuehnelt, J. Trace Elem. Med. Biol., 2015, 29, 83-90. M. Vinceti, P. Grill, C. Malagoli, T. Filippini, S. Storani, M. Malavolti and B. Michalke, J. Trace Elem. Med. Biol., 2015, 31, 1-10.

S. Kokarnig, D. Kuehnelt, M. Stiboller, U. Hartleb and K. A. Francesconi, Anal. Bioanal. Chem., 2011, 400, 2323-2327. S. Cuello, S. Ramos, R. Mateos, M. A. Martín, Y. Madrid, C. Cámara, L. Bravo and L. Goya, Anal. Bioanal. Chem., 2007, 389, 2167-2178. A. A. Turanov, R. A. Everley, S. Hybsier, K. Renko, L. Schomburg, S. P. Gygi, D. L. Hatfield and V. N. Gladyshev, PLoS One, 2015, 10, 1-9. P. Traar, F. Belaj and K. A. Francesconi, Aust. J. Chem., 2004, 57, 1051-1053. J. L. Hoffman, J. Chromatogr. A, 1991, 588, 211-216. B. Gammelgaard and O. Jøns, J. Anal. At. Spectrom., 1999, 14, 867-874.

J. Vogl and W. Pritzkow, Mapan, 2010, 25, 135-164.

P. Rodríguez-González, J. M. Marchante-Gayón, J. I. García Alonso and A. Sanz-Medel, Spectrochim. Acta Part B At. Spectrosc., 2005, 60, 151-207.

B. Meermann, M. Bockx, A. Laenen, C. Van Looveren, F. Cuyckens and F. Vanhaecke, Anal. Bioanal. Chem., 2012, 402, 439-448.

L. Hinojosa Reyes, J. M. Marchante Gayón, J. I. García Alonso and A. Sanz-Medel, J. Anal. At. Spectrom., 2003, 18, 11-16.

K. G. Heumann, Int. J. Mass Spectrom. Ion Process., 1992, 118-119, 575-592.

D. Juresa, D. Kuehnelt and K. A. Francesconi, Anal. Chem., 2006, 78, 8569-8574.

K. Flouda, J. M. Dersch, C. Gabel-Jensen, S. Stürup, S. Misra, M. Björnstedt and B. Gammelgaard, Anal. Bioanal. Chem., 2016, 408, 2293-2301.

B. Jackson, A. Liba and J. Nelson, J. Anal. At. Spectrom., 2015, 30, 1179-1183.

L. Balcaen, E. Bolea-Fernandez, M. Resano and F. Vanhaecke, Anal. Chim. Acta, 2015, 894, 7-19.

C. S. Hoefig, K. Renko, J. Köhrle, M. Birringer and L. Schomburg, J. Nutr. Biochem., 2011, 22, 945-955. A. P. Kipp, J. Frombach, S. Deubel and R. Brigelius-Flohé, Methods Enzymol., 2013, 527, 87-112.

D. Kuehnelt, N. Kienzl, P. Traar, N. H. Le, K. A. Francesconi and T. Ochi, Anal. Bioanal. Chem., 2005, 383, 235-246.

C. Gabel-Jensen and B. Gammelgaard, J. Anal. At. Spectrom., 2010, 25, 414-418.

H. Goenaga Infante, S. P. Joel, E. Warburton, C. Hopley, R.
Hearn and S. Juliger, J. Anal. At. Spectrom., 2007, 22, 888896.

C. Gabel-Jensen, S. A. Bak, F. R. Lauritsen, H. R. Hansen, L. Badolo and B. Gammelgaard, J. Anal. At. Spectrom., 2009, 24, 949-952.

J. Far, H. Preud'homme and R. Lobinski, Anal. Chim. Acta, 2010, 657, 175-190.

M. Dernovics, J. Far and R. Lobinski, Metallomics, 2009, 1, 317-329.

S. J. Fairweather-Tait, Y. Bao, M. R. Broadley, R. Collings, D. Ford, J. E. Hesketh and R. Hurst, Antioxid. Redox Signal., 2011, 14, 1337-1383.

E. Dumont, Y. Ogra, F. Vanhaecke, K. T. Suzuki and R. Cornelis, Anal. Bioanal. Chem., 2006, 384, 1196-1206. 


\section{Electronic supplementary information}

Tracing cytotoxic effects of small organic Se species in human liver cells back to total cellular Se and Se metabolites

T.A. Marschall, N. Kroepfl, K.B. Jensen, J. Bornhorst, B. Meermann, D. Kuehnelt and T. Schwerdtle

Supplementary table 1: ICP-QQQ-MS parameters.

\begin{tabular}{ll}
\hline RF power & $1550 \mathrm{~W}$ \\
Reflected power & $<5 \mathrm{~W}$ \\
Plasma gas flow & $15 \mathrm{~L} / \mathrm{min}$ \\
Carrier gas flow & $1 \mathrm{~L} / \mathrm{min}$ \\
Auxiliary gas flow & $0.9 \mathrm{~L} / \mathrm{min}$ \\
Collision and reaction gas mixture in the & Oxygen $(99.999 \%) 0.4 \mathrm{~mL} / \mathrm{min}$ \\
CRC & Hydrogen $(99.999 \%) 1 \mathrm{~mL} / \mathrm{min}$ \\
$m / z(Q 1 \rightarrow$ Q2) & $80 \rightarrow 96$ used for quantification \\
& $80 \rightarrow 80$ interference monitoring \\
& $78 \rightarrow 94$ interference monitoring \\
& $78 \rightarrow 78$ interference monitoring \\
& $77 \rightarrow 93$ spike \\
Integration time & $77 \rightarrow 77$ spike \\
Number of sweeps & $0.1 \mathrm{~s}$ \\
Sample flow & 100 \\
Isopropanol flow & $0.33 \mathrm{~mL} / \mathrm{min}$ \\
\hline
\end{tabular}

Supplementary table 2: Quantitative investigation of the degradation of unknown species I and II applying HPLC-ICP-QQQ-MS analysis every 120 min with a $50 \mu \mathrm{M}$ MeSeCys HepG2 cell lysate (4 d), which was stored at room temperature between the runs. As the volatile species DMSe shows enhanced response, ${ }^{31}$ it was not included. (See also figure 3 )

\begin{tabular}{|c|c|c|c|c|}
\hline \multirow[b]{2}{*}{ Run \# } & \multicolumn{3}{|c|}{ Concentration in the measured solution $[\mu \mathrm{g} \mathrm{Se/L]}$} & \multirow[b]{2}{*}{ Sum $[\mu g \mathrm{Se} / \mathrm{L}]$} \\
\hline & MeSeCys & Unknown species I & Unknown species II & \\
\hline 1 & 12.9 & 2.7 & 21.4 & 37.0 \\
\hline 2 & 27.2 & 1.4 & 7.1 & 35.7 \\
\hline 3 & 34.0 & 0.7 & & 34.7 \\
\hline 4 & 34.5 & & & 34.5 \\
\hline
\end{tabular}


Supplementary table 3: Percentual comparison of total cellular Se concentrations to the amount of speciated Se compounds.

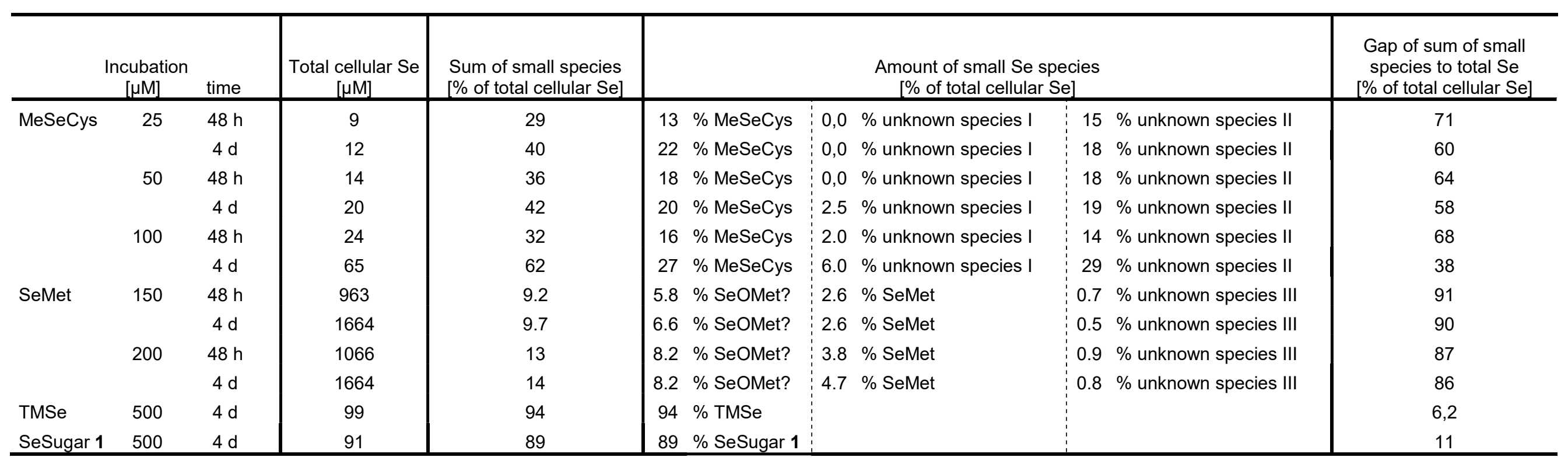




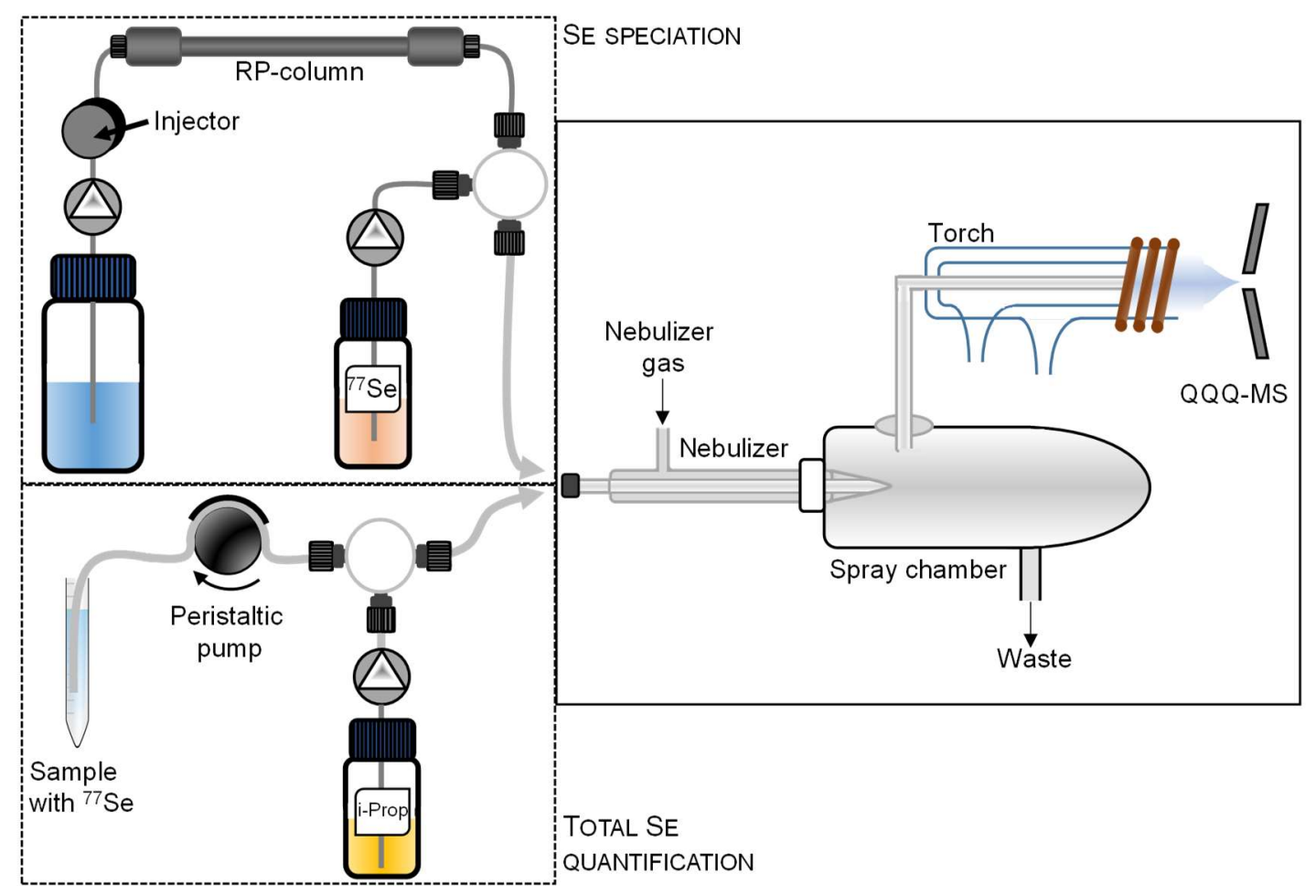

Supplementary figure 1: Instrumental set-up for Se speciation and total Se quantification using ID(HPLC-)ICP-QQQ-MS. 

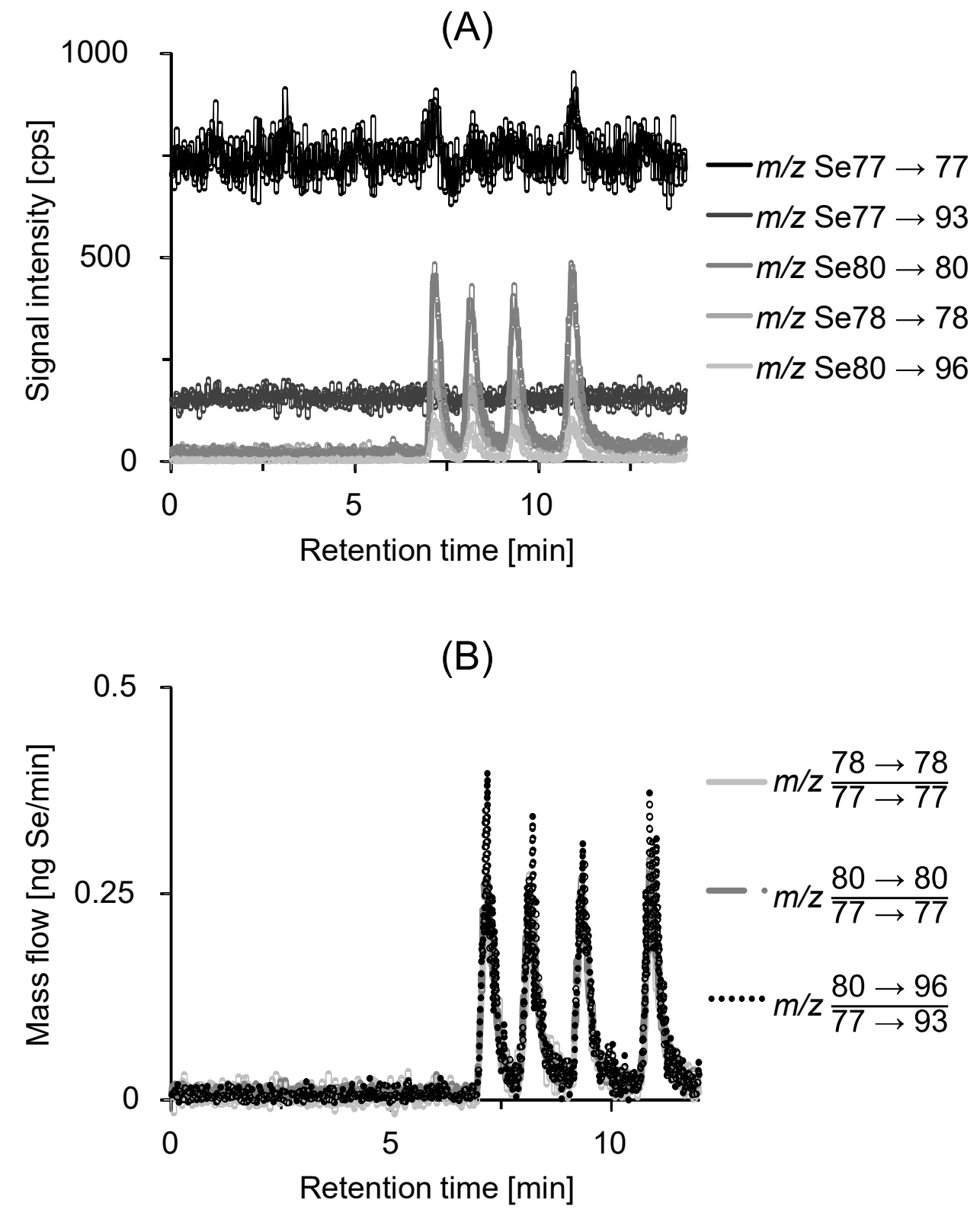

Supplementary figure 2: Standard reference chromatogram of $5 \mu \mathrm{g} / \mathrm{L} \mathrm{MeSeCys} \mathrm{(7.3} \mathrm{min),} \mathrm{TMSe} \mathrm{(8.4}$ $\mathrm{min})$, SeMet (9.6 $\mathrm{min})$ and SeSugar $1(11.1 \mathrm{~min})(A)$ and the corresponding mass flow chromatogram (B). Chromatographic separation was performed on a YMC-TriartPFP column $(3 \mu \mathrm{m}, 3 \times 250 \mathrm{~mm})$ at 30 ${ }^{\circ} \mathrm{C}$ with $250 \mu \mathrm{L} / \mathrm{min} 20 \mathrm{mM}$ ammonium formate $(\mathrm{pH} 3,3 \%$ methanol) as mobile phase. 